\title{
Endothelial cells regulate p53-dependent apoptosis of neural progenitors after irradiation
}

\author{
F Lu', Y-Q Li', I Aubert ${ }^{2}$ and CS Wong,
}

Endothelial cells represent an important component of the neurogenic niche and may regulate self-renewal and differentiation of neural progenitor cells (NPCs). Whether they have a role in determining the apoptotic fate of NPCs after stress or injury is unclear. NPCs are known to undergo p53-dependent apoptosis after ionizing radiation, whereas endothelial cell apoptosis after irradiation is dependent on membrane acid sphingomyelinase (ASMase) and is abrogated in sphingomyelin phosphodiesterase 1 (smpd1)- (gene that encodes ASMase) deficient mice. Here we found that p53-dependent apoptosis of NPCs in vivo after irradiation was inhibited in smpd1-deficient mice. NPCs cultured from mice, wild type $(+I+)$ or knockout $(-I-)$, of the smpd1 gene, however, demonstrated no difference in apoptosis radiosensitivity. NPCs transplanted into the hippocampus of smpd1 - I - mice were protected against apoptosis after irradiation compared with those transplanted into smpd1 $+I+$ mice. Intravenous administration of basic fibroblast growth factor, which does not cross the blood-brain barrier, known to protect endothelial cells against apoptosis after irradiation also attenuated the apoptotic response of NPCs. These findings provide evidence that endothelial cells may regulate p53-dependent apoptosis of NPCs after genotoxic stress and add support to an important role of endothelial cells in regulating apoptosis of NPCs after injury or in disease.

Cell Death and Disease (2012) 3, e324; doi:10.1038/cddis.2012.59; published online 21 June 2012

Subject Category: Internal Medicine

Multipotent neural progenitor cells (NPCs) or stem cells are present in the adult central nervous system (CNS). In the adult rodent brain, these multipotent neural progenitors are well characterized in two regions: the subventricular zone (SVZ) of the lateral ventricles, and the subgranular zone (SGZ) of the dentate gyrus in the hippocampus. ${ }^{1}$ The microenvironment or niche is a key regulator of the behavior of NPCs in vivo. Although the anatomic and functional components of the neurogenic niche remain to be determined, endothelial cells are a key component of the neurogenic niche. ${ }^{2,3}$ Adult NPCs are closely apposed to laminin-containing extracellular matrix surrounding a rich plexus of endothelial cells and blood vessels. ${ }^{3}$ Endothelial cells have been shown to release soluble factors that stimulate self-renewal of NPCs and neurogenesis. ${ }^{2}$

Alterations in the p53tumor-suppressor gene represent one of the most common genetic abnormalities in human tumors. A major pathway that is upregulated in response to ionizing radiation is the p53 pathway. In addition to DNA-damage repair, p53 has been shown to regulate a variety of cellular processes including cell-cycle arrest and apoptosis, and p53 alterations have been linked to tumor-cell resistance to radiation. ${ }^{4}$ In response to ionizing radiation, NPCs undergo apoptosis within hours, ${ }^{5-8}$ a process known to be mediated by p53. ${ }^{6,9}$ Apoptosis of NPCs in both the SVZ and the dentate gyrus of the hippocampus was abrogated in p53-deficient mice. ${ }^{6,8}$ Endothelial cells also undergo acute apoptosis after ionizing radiation. In contrast to radiation-induced apoptosis of NPCs, which is mediated by p53, endothelial cell apoptosis is mediated by membrane damage through the second messenger ceramide generated from membrane sphingomyelin following activation of acid sphingomyelinase (ASMase). ${ }^{10}$ Radiation-induced apoptosis of endothelial cells, including those in the CNS, is attenuated in sphingomyelin phosphodiesterase 1 (smpd1)- (gene that encodes ASMase) deficient mice. ${ }^{8,11,12}$ Radiation-induced apoptosis of endothelial cells has also been shown to be inhibited by intravenous administration of basic fibroblast growth factor (bFGF). ${ }^{8,11,12}$

It remains unknown whether endothelial cell apoptosis following genotoxic stress results in damage of the neurogenic niche and has an effect on the apoptotic fate of NPCs. Here we employed a genetic approach using smpd1 transgenic mice and a pharmacological approach by intravenous bFGF to address whether endothelial cell apoptosis has a role in apoptosis of NPCs after irradiation. We showed that abrogating endothelial cell apoptosis resulted in inhibition of

\footnotetext{
${ }^{1}$ Department of Radiation Oncology, Sunnybrook Health Sciences Centre, Toronto, Ontario, Canada and ${ }^{2}$ Department of Laboratory Medicine and Pathobiology, University of Toronto, Toronto, Ontario, Canada

${ }^{*}$ Corresponding author: CS Wong, Department of Radiation Oncology, Sunnybrook Health Sciences Centre, 2075 Bayview Avenue, Toronto, Ontario M4N 3M5, Canada. Tel: + 1416480 4619; Fax: + 1416480 6002; E-mail: shun.wong@ @unnybrook.ca

Keywords: neural progenitors; endothelial cells; apoptosis; irradiation; p53

Abbreviations: ANOVA, analysis of variance; ASMase, acid sphingomyelinase; bFGF, basic fibroblast growth factor; BrdU, bromodeoxyuridine; CNS, central nervous system; DAPI, 4', 6-diamidino-2-phenylindole; DCX, doublecortin; EGF, epidermal growth factor; eGFP, enhanced green fluorescent protein; GC, galactocerebroside; GFAP, glial fibrillary acidic protein; HIF-1, hypoxia-inducible factor-1; MAP2, microtubule-associated protein-2; NeuN, Neuronal nuclei; NPCs, neural progenitor cells; SGZ, subgranular zone; smpd1, sphingomyelin phosphodiesterase 1; SVZ, subventricular zone; TUNEL, terminal deoxynucleotidyl transferase-mediated dUTP nick-end labeling

Received 09.12.11; revised 27.4.12; accepted 30.4.12; Edited by D Bano
} 
p53-dependent apoptosis of NPCs after irradiation. These results support the notion of a key role of endothelial cells in regulating the NPC survival after genotoxic stress.

\section{Results}

p53-mediated apoptosis of NPCs after irradiation is smpd1 genotype-dependent. Spontaneous apoptosis was rarely observed in the dentate gyrus of nonirradiated animals regardless of $p 53$ genotype. Within $4 \mathrm{~h}$ after irradiation, apoptotic cells appeared in the SGZ of the dentate gyrus of mice wild type for $p 53(+/+)$. These cells demonstrated characteristic nuclear condensation and fragmentation of apoptosis upon 4', 6-diamidino-2-phenylindole (DAPI) nuclear staining (Supplementary Figure 1). The peak response was observed at $8 \mathrm{~h}$ after irradiation, and the response disappeared by $24 \mathrm{~h}$. There was an intermediate response observed in $p 53+/-$ mice, and the apoptotic response was almost completely abrogated in p53-/mouse dentate gyrus up to $24 \mathrm{~h}$ after irradiation as we previously reported. ${ }^{8}$
Endothelial cells are enriched in secretory ASMase, ${ }^{13}$ and there is a large body of literature on the dependence of radiation-induced apoptosis in endothelial cells by the ASMase pathway. ${ }^{14}$ Radiation-induced apoptosis of endothelial cells in the mouse brain and spinal cord is attenuated in smpd1+/- and smpd1-/ - mice, which are deficient in ASMase. ${ }^{11,12}$ In the mouse dentate gyrus, radiation-induced apoptosis of endothelial cells peaked at about $8 \mathrm{~h}$ and disappeared by $24 \mathrm{~h}$. Consistent with the dependence of radiation-induced endothelial cell apoptosis on the ASMase/ ceramide pathway, the number of CD31-labeled apoptotic cells observed in the dentate gyrus was smpd1 genotype $(P<0.001$, Supplementary Figure 2$)$, in addition to being radiation dose-dependent $(P<0.001)$.

We next irradiated smpd1+/+, smpd1+/- and smpd1-/ - mice with graded single doses of $\mathrm{X}$-rays to determine if the apoptotic response of NPCs could be dependent on ASMase status. In the SGZ, apoptotic cells were rarely observed in nonirradiated mice regardless of smpd1 genotype (Figure 1). After irradiation, apoptotic subgranular cells were observed at $4 \mathrm{~h}$. The apoptotic
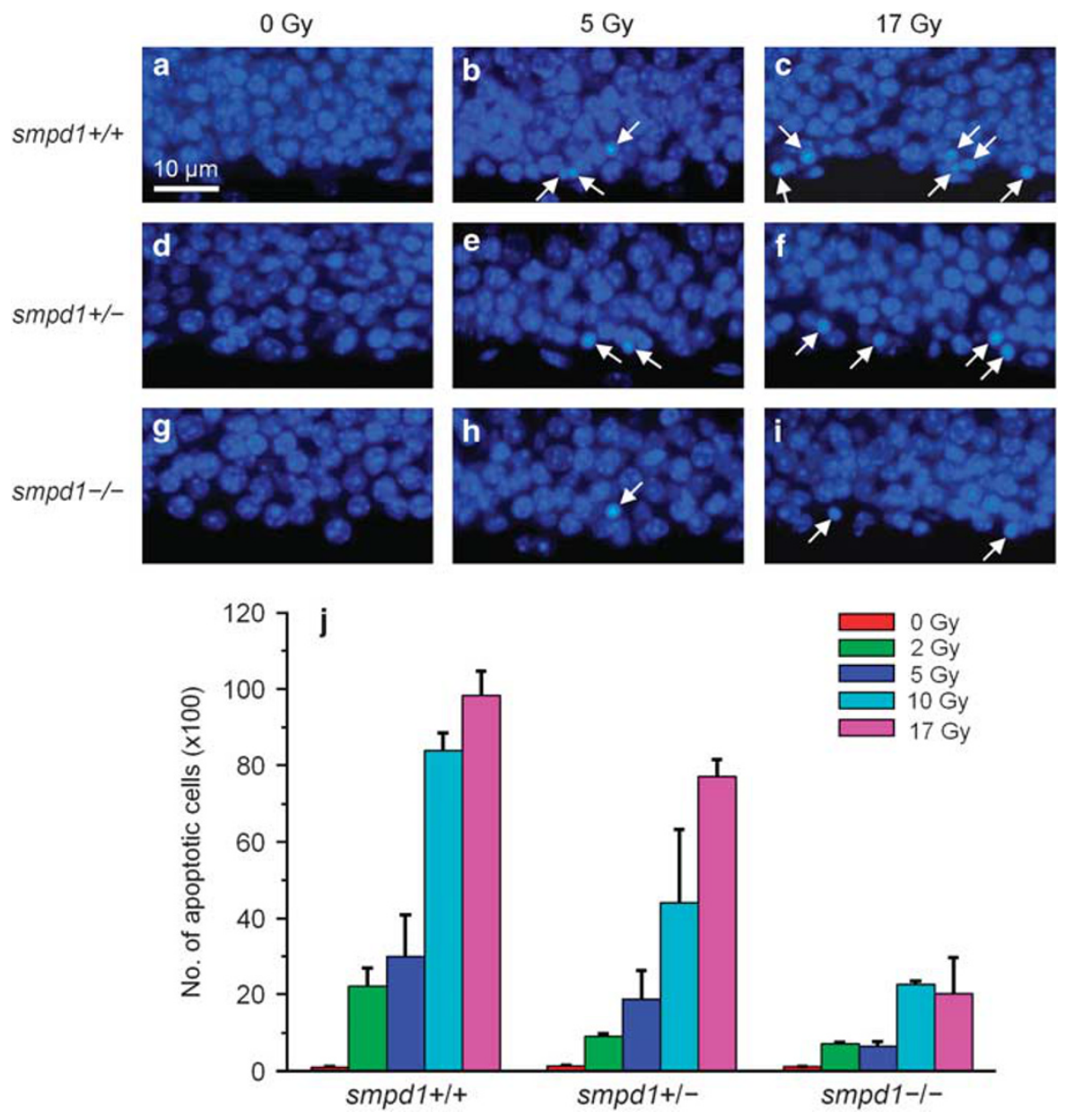

Figure 1 The apoptotic response of subgranular cells in the SGZ of the dentate gyrus after irradiation is radiation dose- and smpd1 genotype-dependent. Cells in the SGZ of the dentate gyrus of $s m p d 1+I+(\mathbf{a}-\mathbf{c})$, smpd1 $+/-(\mathbf{d}-\mathbf{f})$ and $s m p d 1-I-(\mathbf{g}-\mathbf{i})$ mice undergo radiation dose-dependent apoptosis at $8 \mathrm{~h}$ after irradiation. Apoptotic cells (arrows) are identified by their characteristic nuclear condensation and fragmentation using DAPI nuclear staining. The number of apoptotic cells estimated by stereology is radiation dose $(P<0.0001$, two-way ANOVA; $n=$ minimum of 3 per dose group) and smpd1 genotype- dependent $(P<0.0001)$. (j) Data represent means \pm S.E.M 
response peaked at $8 \mathrm{~h}$ and disappeared by $24 \mathrm{~h}$. An apparent reduction in apoptotic subgranular cells was observed in smpd1-/- mice compared with smpd1+/+ mice (Figures $1 \mathrm{a}-\mathrm{i}$ ). At $8 \mathrm{~h}$ after irradiation, the number of apoptotic subgranular cells was radiation dose- $(P<0.0001$, two-way analysis of variance (ANOVA) and smpd1 genotype-dependent $(P<0.0001)$ (Figure 1j). There was no evidence of a delayed apoptotic response in subgranular cells in smpd1 + Iand smpd $1-/$ - mice. By $24 \mathrm{~h}$ after irradiation, apoptotic cells were rarely observed regardless of smpd1 genotype.

Similar results were observed using caspase- 3 immunofluorescence (Figures 2a-l) or terminal deoxynucleotidyl transferase-mediated dUTP nick-end labeling (TUNEL) assay (Figures $2 \mathrm{~m}-\mathrm{x}$ ) to identify apoptotic cells. A significant reduction of subgranular cell apoptosis was observed in smpd1-I- mice compared with smpd1+/+ mice after 17 Gy (Figures 2y and z).

Apoptotic cells in the SGZ after irradiation have previously been shown to be NPCs. ${ }^{8,15}$ Here we also showed that they were immunoreactive for phenotypic markers of NPCs, such as doublecortin (DCX), nestin, Sox2 and musashi-1 (Figures $3 a-1)$, regardless of smpd1 genotype. In contrast, they failed to show immunoreactivity for markers of mature neurons, oligodendrocytes and astrocytes, namely neuronal nuclei (NeuN), galactocerebroside (GC) and glial fibrillary acidic protein (GFAP), respectively (Figures $3 m-u$ ).

Radiation-induced apoptosis of NPCs in vitro is independent of smpd1. To determine whether the regulation of apoptosis after irradiation by the ASMase pathway could be an intrinsic property of NPCs, we assessed the in vitro apoptotic response of NPCs cultured from the adult brain of 8-10-week-old smpd1+/+, smpd1-I-, p53+/+ and p53-I- mice. We first generated neurospheres from the brain of smpd1 $+/+$, smpd1-/ $1-, p 53+/+$ and $p 53-/-$ mice. Immunocytochemistry of cells dissociated from neurospheres demonstrated immunostaining for nestin, Sox2 and musashi-1, phenotypic markers of NPCs (Supplementary Figure 3). These cells also demonstrated multipotential properties regardless of smpd1 and p53 genotype. When cultured in the differentiation medium, they were able to generate cells that demonstrated immunoreactivity for GC GFAP and microtubule-associated protein-2 (MAP2) (Supplementary Figure 4).

After irradiation, many NPCs in vitro from $s m p d 1+/+$, smpd1-/ - or $p 53+/+$ mice were noted to demonstrate characteristic nuclear condensation and fragmentation upon DAPI or TUNEL staining (Figure 4a). In contrast, there was no evidence of an apoptotic response in NPCs cultured from p53- / - mice after irradiation. The apoptotic cells demonstrated immunoreactivity for musashi-1 and Sox2, phenotypic markers for NPCs (Supplementary Figures $5 a-f$ ). Flow cytometric analysis of TUNEL-positive cells revealed an apoptotic response in NPCs from smpd1+/+, smpd1- / and $p 53+/+$ mice, but not in $p 53-/-$ mice at $24 \mathrm{~h}$ after $5 \mathrm{~Gy}$, and there was no apparent difference in the apoptotic response in smpd1+/+ NPCs compared with smpd1-/NPCs after irradiation (Figures $4 \mathrm{~b}$ and $\mathrm{c}$ ). The number of apoptotic cells based on nuclear morphology using DAPI (Figure 4d) or TUNEL (Figure $4 \mathrm{e}$ ) also demonstrated a significant increase in the percent apoptotic cells in NPCs regardless of smpd1 status (radiation dose, $P<0.0001$; smpd1 genotype, not significant; two-way ANOVA). NPCs from $p 53+/+$ mice demonstrated a significant increase in the percent TUNEL or DAPI-positive apoptotic cells after $5 \mathrm{~Gy}$ compared with nonirradiated controls.

Transplanted neural progenitors have an attenuated apoptotic response in smpd1 - I- mouse hippocampus after irradiation. To provide evidence that a disrupted microenvironment after irradiation might contribute to the apoptotic response of NPCs in vivo, we transplanted bromodeoxyuridine (BrdU)-labeled NPCs cultured from enhanced green fluorescent protein (eGFP) mice into the hippocampus of $s m p d 1+/+$ and smpd1-/- mice and quantified the apoptotic response of transplanted cells after irradiation. A decrease in the apoptotic response of transplanted progenitors in smpd1-/- mouse brain compared with smpd1 $+/+$ mice would be consistent with a role for the neurogenic niche in regulating NPC apoptosis after irradiation.

We first established a method to transplant NPCs stereotactically into the hippocampus of 6-week-old mice. NPCs were cultured from the brain of Tg/CAG-EGFP/B5Nagy/J mice that express eGFP. NPCs were allowed to incorporate BrdU $(1 \mu \mathrm{M})$ for 2 days prior to transplantation as a second method to identify transplanted cells. The BrdU incorporation was found to have no effect on cell viability prior to transplantation. We confirmed the multipotential properties of these eGFP cells by their ability to differentiate into oligodendrocytes, astrocytes and neurons in vitro (Supplementary Figure 6).

Similar to the in vitro apoptotic response of NPCs cultured from smpd1 $+/+$, smpd $1-/-$ and $p 53+/+$ mice, irradiated (5Gy) NPCs from eGFP mice show a significant apoptotic response at $24 \mathrm{~h}$ compared with nonirradiated controls (Supplementary Figure 7).

BrdU-labeled eGFP NPCs $\left(2.5 \times 10^{5}\right.$ cells $)$ were transplanted into the right and left hippocampus of 6-week-old smpd1+/+ and smpd1-/- mice. BrdU-labeled eGFPNPCs could be identified in mouse hippocampus at 4 weeks after transplantation. Some transplanted cells showed positive staining for Nestin and some showed DCX or NeuN expression, confirming the neuronal differentiating potential of transplanted NPCs (Supplementary Figure 8).

Four weeks after transplantation of eGFP cells, mice (10-week-old) were given 0 or 17 Gy whole-brain irradiation. In the nonirradiated hippocampus of smpd1+/+ and smpd1-/- mice, we did not observe any BrdU- or eGFPpositive apoptotic cells. At $8 \mathrm{~h}$ after irradiation, some BrdU and eGFP cells demonstrated characteristic nuclear condensation of apoptosis (Figures $5 \mathrm{a}-\mathrm{c}$ ). We observed no significant difference in the total number of BrdU-labeled or eGFPpositive cells in smpd1 $+/+$ mouse hippocampus compared with smpd1-/- mice (Figure $5 \mathrm{~d}$ ). However, there was a significant decrease in the number (Figure $5 \mathrm{e}$ ) and percentage (Figure 5f) of BrdU- or eGFP-positive apoptotic cells in the dentate gyrus of smpd1-/- mice compared with smpd1 $+/+$ mice. We failed to observe any apoptotic eGFP- or BrdU-labeled cells in nonirradiated mice. 

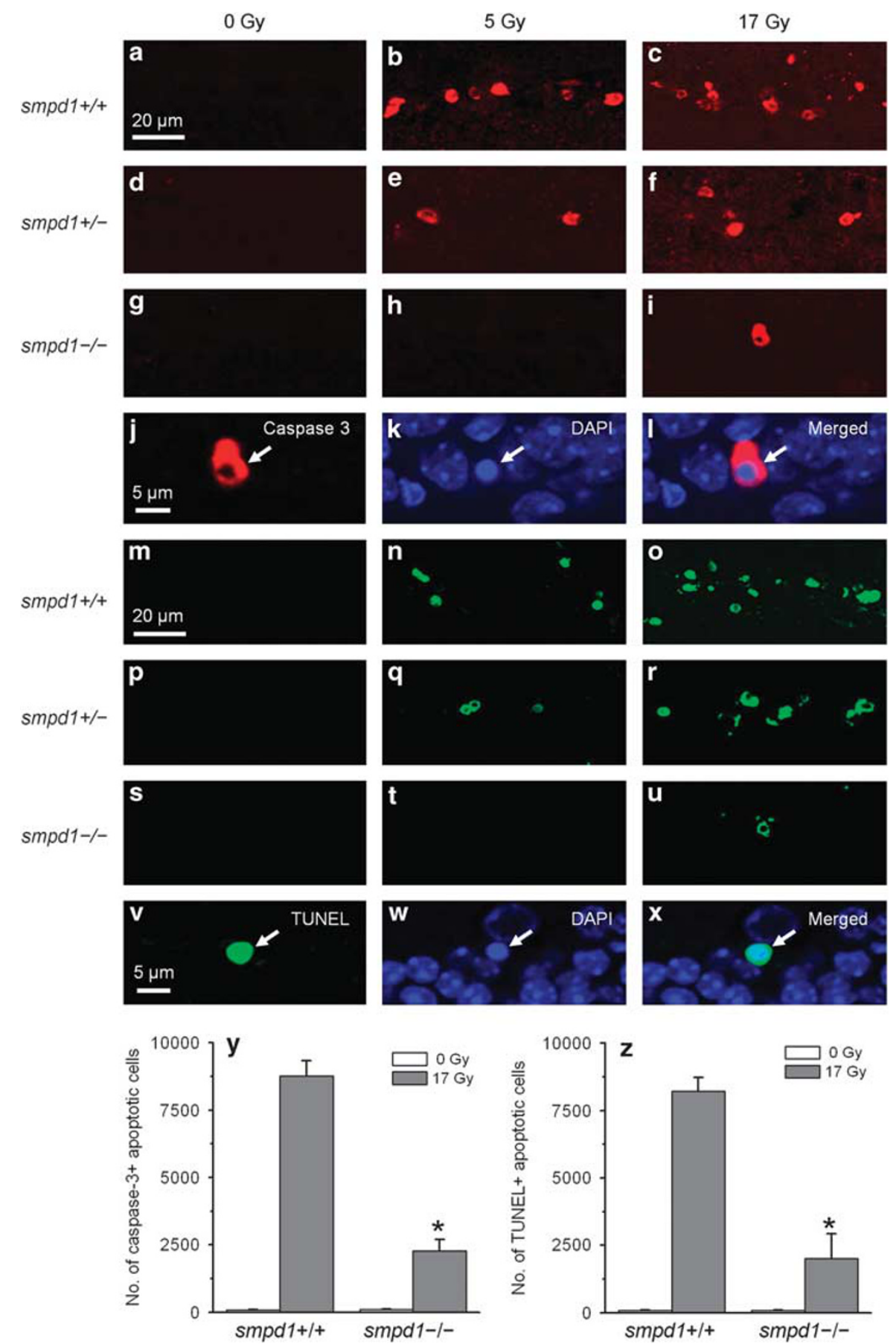

Figure 2 The apoptotic response of subgranular cells in the SGZ of the dentate gyrus after irradiation is attenuated in smpd1-deficient mice. Caspase-3 immunoreactive cells (red, $\mathbf{a}-\mathbf{i}$ ) are seen in the SGZ of the smpd1 $+/+$ mouse dentate gyrus after 5 and $17 \mathrm{~Gy}(\mathbf{a}-\mathbf{c})$. The response is decreased in smpd1 $+/-$ mice (d-f), and further attenuated in smpd1-/- mice (g-i). A caspase-3 positive cell (arrow, j) shows characteristic nuclear condensation of apoptosis (DAPI, $\mathbf{k}$; merged, I). A similar dependence of the apoptotic response of subgranular cells on smpd1 status is observed using TUNEL to identify apoptotic cells (green, $\mathbf{m}-\mathbf{x}$ ). A TUNEL-positive apoptotic cell (arrow, $\mathbf{v}$ ) demonstrates nuclear condensation after DAPI nuclear staining (arrow, w; merged, $\mathbf{x})$. A significant reduction in caspase-3 (y) or TUNEL-positive subgranular cells (z) is observed in smpd1-/- mice compared with smpd1 $+I+$ mice after irradiation $\left({ }^{*} P<0.01, t\right.$-test). The number of apoptotic cells in a minimum of three mice is estimated by stereology. Data represent means \pm S.E.M

To exclude any confounding effect of the transplantation procedure on the subsequent apoptotic response of NPCs after irradiation, we compared the number of endogenous apoptotic subgranular cells in non-tranplanted and transplanted smpd $1+/+$ mice at $8 \mathrm{~h}$ after $17 \mathrm{~Gy}$. There was no significant difference in total number of endogenous apoptotic subgranular cells $(14285 \pm 2920, n=3)$ in transplanted mice compared with that in non-transplanted mice 

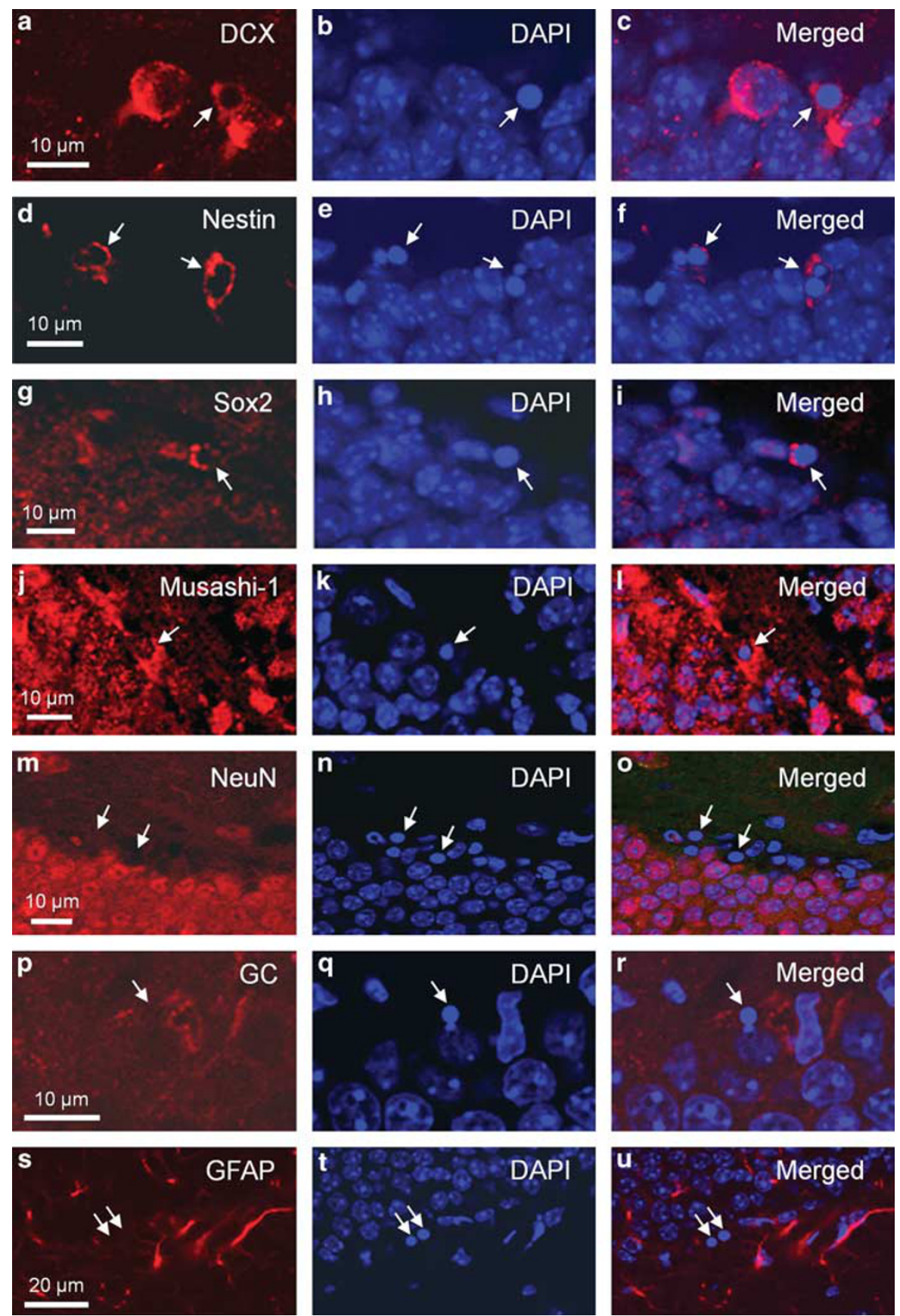

Figure 3 Apoptotic cells in the SGZ of the dentate gyrus after irradiation express phenotypic markers for neural progenitors. Apoptotic cells (arrows) demonstrate immunoreactivity for DCX $(\mathbf{a}-\mathbf{c})$, nestin $(\mathbf{d}-\mathbf{f})$, Sox2 $(\mathbf{g}-\mathbf{i})$ or musashi-1 $(\mathbf{j}-\mathbf{l})$, phenotypic markers of neural progenitors. Apoptotic cells are identified by their characteristic morphological features of nuclear condensation and fragmentation after DAPI nuclear staining (arrows, $\mathbf{b}, \mathbf{e}, \mathbf{h}$ and $\mathbf{k}$ ). Colocalization of immunoreactivity of phenotypic markers and DAPI are shown in the merged pictures $(\mathbf{c}, \mathbf{f}, \mathbf{i}$ and $\mathbf{l})$. The apoptotic cells (arrows) are negative for NeuN ( $\mathbf{m}-\mathbf{0})$, GC ( $\mathbf{p}-\mathbf{r})$ and GFAP (s-u), markers for neurons, oligodendrocytes and astrocytes, respectively

$(14219 \pm 2915, n=3)$ after irradiation. There was also no significant difference in the very low number of spontaneous apoptotic subgranular cells in nonirradiated transplanted mice compared with that in nonirradiated, non-transplanted age-matched controls.

Intravenous bFGF attenuates apoptosis of the dentate gyrus NPCs after irradiation. The attenuation of the apoptotic response of transplanted cells in smpd1-/mouse hippocampus may be due to some unknown protective effects associated with constitutive knockout of the smpd1 gene after irradiation. Intravenous administration of bFGF has been shown to protect CNS microvessel endothelial cells against apoptosis after irradiation. ${ }^{8,11,12}$ Because bFGF does not cross the blood-brain barrier after intravenous injection, ${ }^{16}$ we used intravenous administration 
of bFGF as a pharmacological approach to determine whether inhibiting apoptosis of endothelial cells by bFGF resulted in attenuation of the apoptotic response of NPCs in the dentate gyrus. Intravenous administration of bFGF alone had no effect on spontaneous apoptosis compared with vehicle controls in the absence of irradiation. At $8 \mathrm{~h}$ after 10
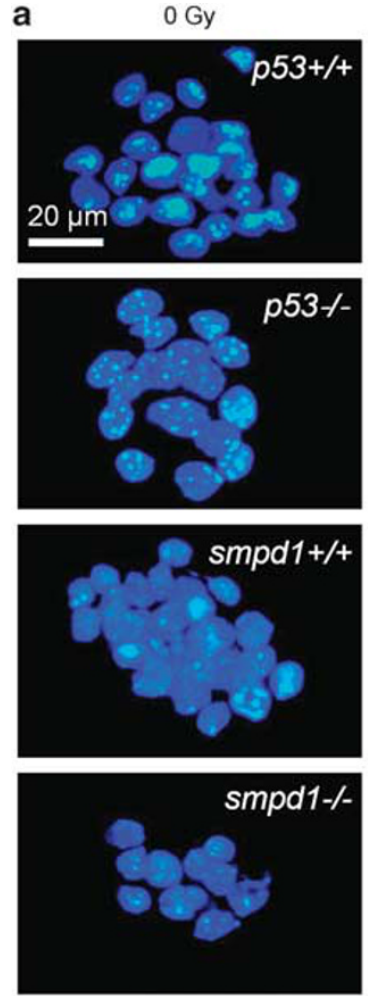

DAPI

b
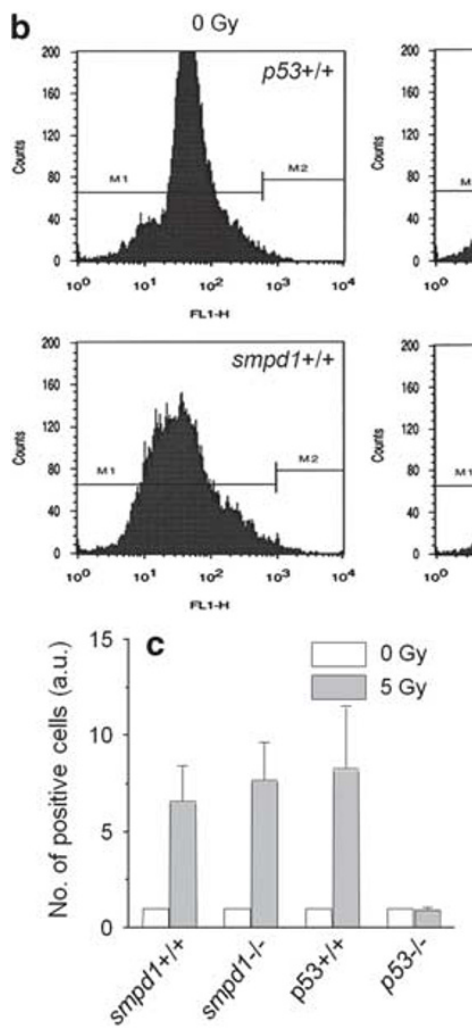

0 Gy
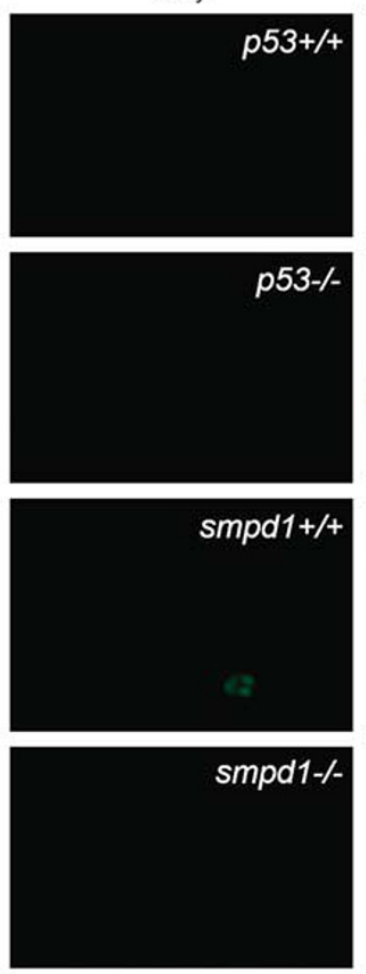

TUNEL

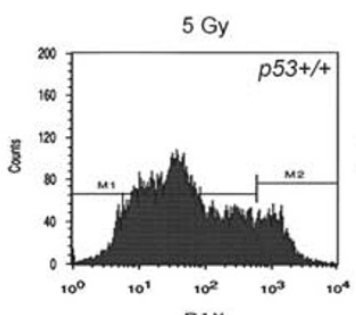

F.1.+1
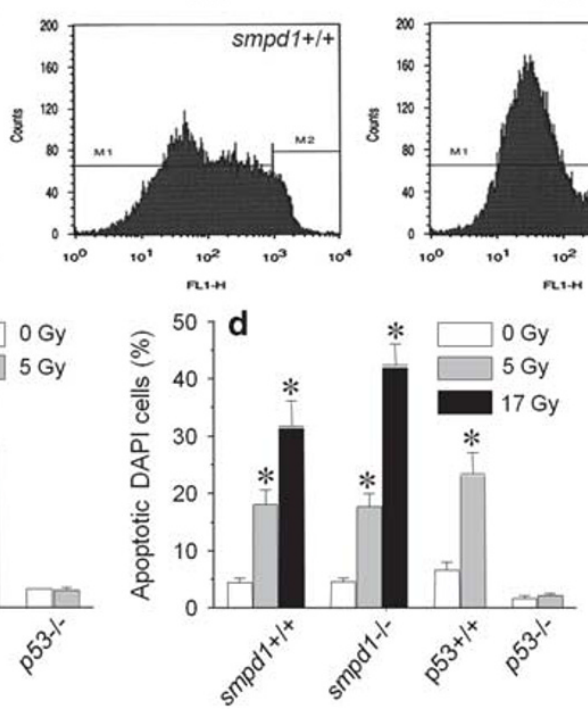

5 Gy

DAPI
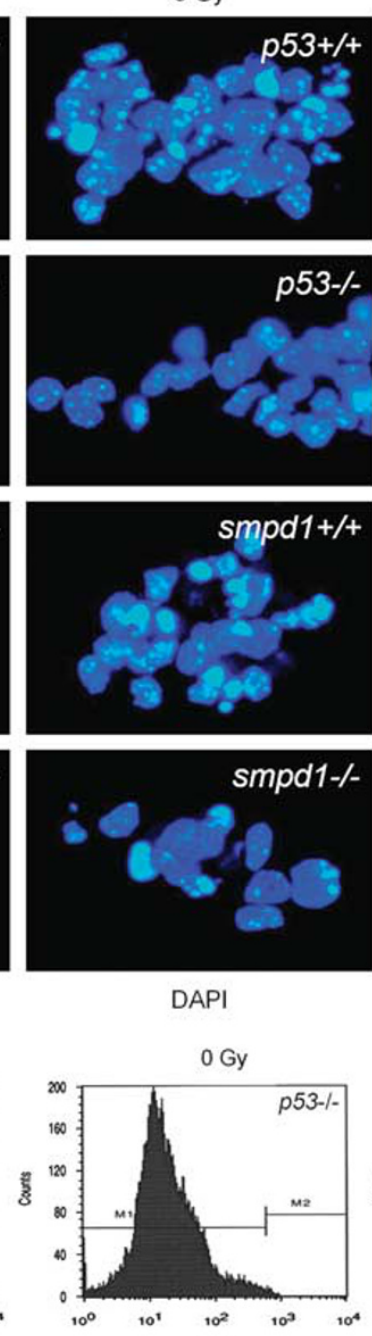

FLt+
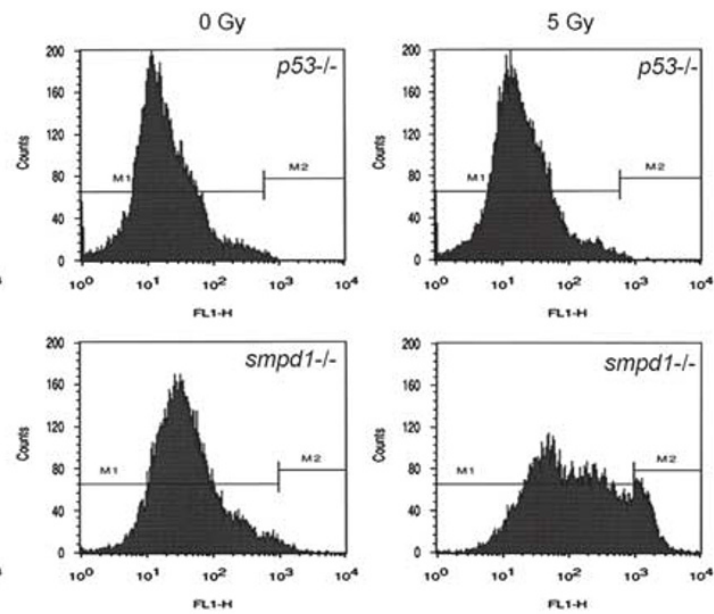

Fit
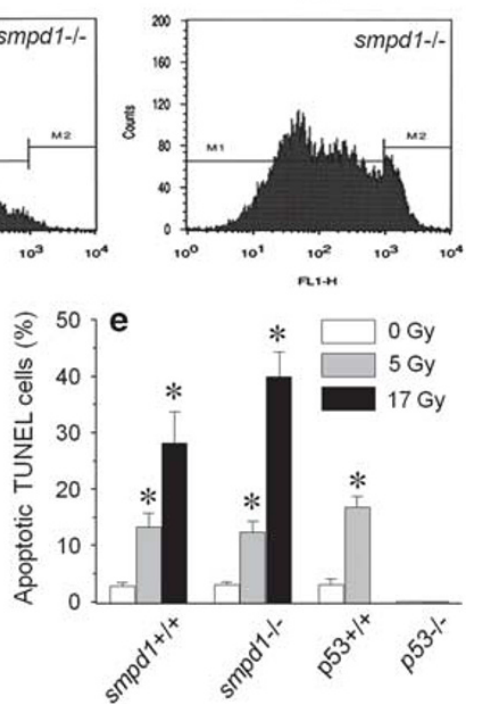
or $17 \mathrm{~Gy}$, the number of apoptotic CD31-positive endothelial cells in the dentate gyrus was radiation dose $(P<0.01$, twoway ANOVA) and bFGF-dependent $(P<0.01$; Table 1$)$. There was an apparent reduction in the number of apoptotic cells in the SGZ of the dentate gyrus in bFGF-treated animals compared with vehicle controls (Figures $6 a-c)$. The number of apoptotic subgranular cells was radiation dose$(P<0.01$, two-way ANOVA) and bFGF-dependent $(P<0.01$; Table 1). There was no evidence of a delayed apoptotic response after bFGF. At $24 \mathrm{~h}$ after irradiation, apoptotic endothelial cells or NPCs were rarely observed in bFGF- or vehicle-treated mice.

A similar attenuation of the radiation-induced apoptotic response in the SGZ after intravenous bFGF was observed using caspase-3 and TUNEL as apoptotic assays
(Figures 6d-i and p). Apoptotic cells in the SGZ demonstrated nestin and DCX immunoreactivity, markers of NPCs after bFGF treatment (Figures 6j-0).

\section{Discussion}

It is now becoming clear that neurons, glia and microvessels are organized into well-structured neurovascular units, which are involved in the regulation of neurological function in health and neurological illness. Neural stem cells and NPCs are apposed to a rich plexus of blood vessels and extracellular matrix that constitute a specialized microenvironment. This neurogenic niche has been implicated in the regulation of cell fate of neural stem cells and NPCs including their selfrenewal and differentiation. ${ }^{2}$ Although recent studies using
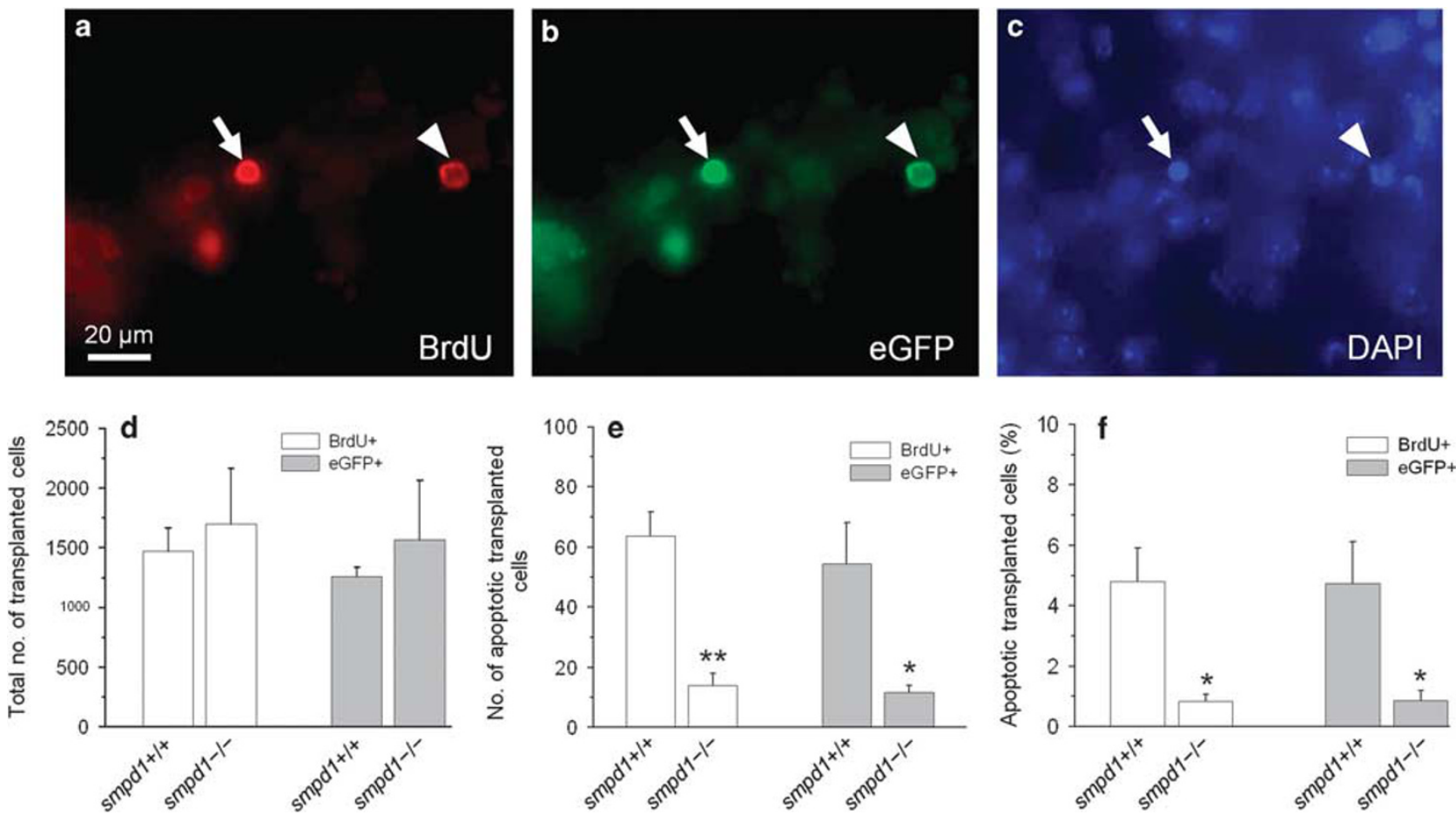

Figure 5 Neural progenitors transplanted into smpd1 - / - mouse hippocampus demonstrate an attenuated apoptotic response after irradiation compared with those transplanted into smpd1 + /+ mice. Neural progenitors cultured from eGFP mice and incubated in BrdU for $48 \mathrm{~h}$ were transplanted into the hippocampus of smpd1 $+/+$ and smpd1 - / - mice. Four weeks after transplantation, the in vivo apoptotic response of transplanted cells was assessed at $8 \mathrm{~h}$ after $17 \mathrm{~Gy}$. An apoptotic BrdU (arrow, red; a) and eGFP-positive (arrow, green; b) transplanted cell demonstrates typical nuclear condensation as seen by DAPI nuclear counterstaining (arrow, blue; $\mathbf{c}$ ), whereas another transplanted cell shows no evidence of apoptosis (arrowhead). Total numbers of eGFP- and BrdU-positive $(+)$ cells observed in the hippocampus of $s m p d 1+I+$ mice are similar compared with those in smpd1 - I - mice at 4 weeks after transplantation (d). After $17 \mathrm{~Gy}$, there is a reduction in the total number (e) and percentage (f) of apoptotic eGFP or BrdU + cells in smpd1 - I - mice compared with smpd1 $+/+$ mice; ${ }^{*} P<0.05 ;{ }^{* *} P<0.01$, one-way ANOVA. Data represent means \pm S.E.M

Figure 4 Neural progenitors cultured from smpd $1+/+$, smpd $1-/$ - and $p 53+/+$, but not those from $p 53-/$ - mice undergo apoptosis in vitro after irradiation. Nonirradiated neural progenitors regardless of genotype show very low level of spontaneous apoptosis (a). Neural progenitors cultured from $p 53+I+, s m p d 1+I+$ and smpd1 - / - mice demonstrate an apoptotic response at $24 \mathrm{~h}$ after $5 \mathrm{~Gy}$, and many cells show nuclear condensation or fragmentations upon DAPI (blue) or TUNEL staining (green). Neural progenitors from $p 53-/$ - mice show no evidence of an apoptotic response after irradiation. (b) Neural progenitors from adult mouse brain were stained using TUNEL and quantified by flow cytometry at $24 \mathrm{~h}$ after a single dose of 0 or $5 \mathrm{~Gy}$. Representative flow cytometry analysis demonstrates that neural progenitors from p53+I+, smpd $1+1+$ and smpd $1-/$ - mice undergo apoptosis after a single dose of 5 Gy, whereas cells from p53-I - mice are resistant (b). Semi-quantitative analysis of flow cytometric data shows an apoptotic response in neural progenitors from smpd $1+I+$, smpd $1-/$ - and $553+/+$ mice after 5 Gy, but no apparent response is seen in p53-I - cells (a.u., arbitrary unit; c). Results represent the means of $\geq 5$ independent experiments. Similar results are observed based on counting of apoptotic cells after DAPI (d) or TUNEL (e) staining. Results represent the means of a minimum of 500 cells counted per experiment in $\geq 5$ independent experiments $\left({ }^{\star} P<0.01\right.$ compared with control, $t$-test). Data represent means \pm S.E.M 
Table 1 Number of apoptotic cells in mouse dentate gyrus at $8 \mathrm{~h}$ after irradiation

\begin{tabular}{|c|c|c|c|}
\hline & & Vehicle & bFGF \\
\hline Number of CD31-positive apoptotic cells ${ }^{a}$ & $\begin{array}{l}\text { 0 Gy } \\
10 \mathrm{~Gy} \\
17 \mathrm{~Gy}\end{array}$ & $\begin{array}{r}2.6 \pm 1.8 \\
77.2 \pm 6.3 \\
124.6 \pm 6.3\end{array}$ & $\begin{array}{r}2.4 \pm 1.8 \\
18.4 \pm 2.6 \\
17.8 \pm 4.6\end{array}$ \\
\hline Number of apoptotic subgranular cells ${ }^{a}$ & $\begin{array}{l}0 \mathrm{~Gy} \\
10 \mathrm{~Gy} \\
17 \mathrm{~Gy}\end{array}$ & $\begin{array}{c}188.2 \pm 15.1 \\
8671.9 \pm 424.9 \\
10425.4 \pm 523.4\end{array}$ & $\begin{array}{c}126.3 \pm 16.1 \\
6152.6 \pm 340.5 \\
4626.8 \pm 1372.2\end{array}$ \\
\hline
\end{tabular}

${ }^{\text {a }} P<0.01$ for irradiation dose and $P<0.01$ for bFGF treatment, two-way ANOVA; $n=$ minimum of three mice per experimental group

three-dimensional whole mounts and computer-based image quantification have begun to provide an improved understanding of the histological architecture of this neurogenic niche ${ }^{17,18}$ the functional role of the various components of this niche remains largely unknown.

lonizing radiation induces an acute apoptotic response in endothelial cells, ${ }^{19,20}$ including those in the CNS. ${ }^{11,12}$ This response is regulated by ASMase. Endothelial cells are enriched in secretory ASMase. Following irradiation, there is a rapid translocation of ASMase from the cytosol into glycosphingolipid- and cholesterol-enriched plasma membrane rafts where ceramide is rapidly generated. Increase in levels of intracellular ceramide serves as a pro-apoptotic secondary messenger. ${ }^{21,22}$ Mice knockout of the smpd1 gene expressed defects in ceramide generation and endothelial cell apoptosis after ionizing radiation. Ionizing radiation and other apoptotic stimuli, such as hypoxia, nutrient deprivation and cytotoxic drugs, may also increase endogenous ceramide levels through mechanisms involving not only ASMase but also ceramide synthase. $^{23}$

Endothelial cell apoptosis has been suggested to mediate normal tissue damage and tumor responses after irradiation. ${ }^{19,20,24}$ bFGF, which inhibited endothelial cell apoptosis in the lungs after irradiation, protected mice against late pneumonitis. $^{24}$ The gastrointestinal syndrome after wholebody radiation could also be prevented when endothelial cell apoptosis was inhibited by smpd1 deficiency or bFGF. ${ }^{19}$ The endothelial apoptotic response mediated by ASMase is considered to be distinct and independent of the p53 pathway. ${ }^{10}$ In the CNS, we previously showed that inhibition of endothelial cell apoptosis after irradiation in smpd1-/mice conferred protection against early blood-brain barrier disruption, whereas barrier disruption was independent of p53 status. $^{12}$

NPCs undergo apoptosis after irradiation. ${ }^{5}$ This response has been well characterized in the two adult neurogenic zones, namely the SGZ of the dentate gyrus of the hippocampus and the SVZ of the lateral ventricles. ${ }^{15}$ This response is mediated by $\mathrm{p} 53 .{ }^{6}$ Here we observed that the apoptotic response of NPCs in vivo, in addition to being mediated by $\mathrm{p} 53$, was dependent on the smpd1 gene. In contrast to p53, which mediates apoptosis of NPCs after irradiation both in vivo and in vitro, NPCs cultured from smpd1+I+ and smpd1-I - mice demonstrated no difference in the apoptosis radiosensitivity in vitro. This smpd1 dependence of radiation-induced apoptosis in vivo is thus not an an intrinsic property of NPCs. This raises the question whether this inhibition is due to attenuation of endothelial cell apoptosis and secondary protection of the NPCs against apoptosis. Alternatively, the protection of NPCs against apoptosis could be due to some unknown phenotypic changes or radiation response perturbation as a result of the constitutive knockout of the smpd1 gene..$^{8,11,12}$ It is unlikely that a difference in NPC proliferation between smpd1 $+/+$ and smpd1-I- mice could account for the difference because irradiation results in cell-cycle arrest and the apoptosis was assessed at $8 \mathrm{~h}$. Our previous data did not demonstrate a difference in the baseline neurogenesis between smpd1 $+/+-$ and smpd1-deficient mice. ${ }^{8,11,12} \mathrm{We}$ did not observe a difference in the number of nestin-positive cells in the SGZ between smpd1+/+ (1825.8 \pm 177.6$)$ and smpd $1-/-$ mice $(1866.7 \pm 465.3, P=0.9, t$-test; $n=3$ mice). There is also no difference in the number of DCX-positive cells in the SGZ in 8-week-old smpd1+/+ $(18645 \pm 1575)$ compared with age-matched smpd1-/ mice (23438 $\pm 5319, P=0.4, t$-test; $n=3$ mice). These results suggest that it is unlikely that there is a difference in the apoptosis-sensitive NPC populations due to smpd1 gene deficiency.

We then used a transplantation and a pharmacological approach to provide evidence that a disrupted microenvironment and endothelial apoptosis after irradiation might modulate the apoptotic response of NPCs in vivo. The lack of a significant difference in the total number of transplanted cells at 5 weeks in smpd1+l+ mouse dentate gyrus compared with smpd1-/- mice does suggest the lack of a difference in the microenvironment of smpd1+/+ compared with smpd1-/- mice insofar as supporting the survival of transplanted cells. Intravenous bFGF, which attenuated the apoptotic response of endothelial cells, also inhibited the apoptotic response of NPCs after irradiation. Taken together, these results provide for the first time that endothelial cells may regulate the p53-dependent apoptotic fate of NPCs after ionizing radiation.

The mechanism for this protective effect remains unknown. lonizing radiation is known to induce an acute disruption of the blood-brain barrier. We previously showed that deficiency of smpd1-/- conferred protection against early barrier disruption after ionizing radiation. ${ }^{12}$ Barrier disruption and the resulting hypoxia may lead to upregulation of hypoxiainducible factor-1 (HIF-1), which has been shown to potentiate radiation-induced apoptosis. There is evidence that p53 is required for HIF-1-dependent apoptotic induction. In tumor cells, HIF-1 promotes p53 phosphorylation at serine 15 in 

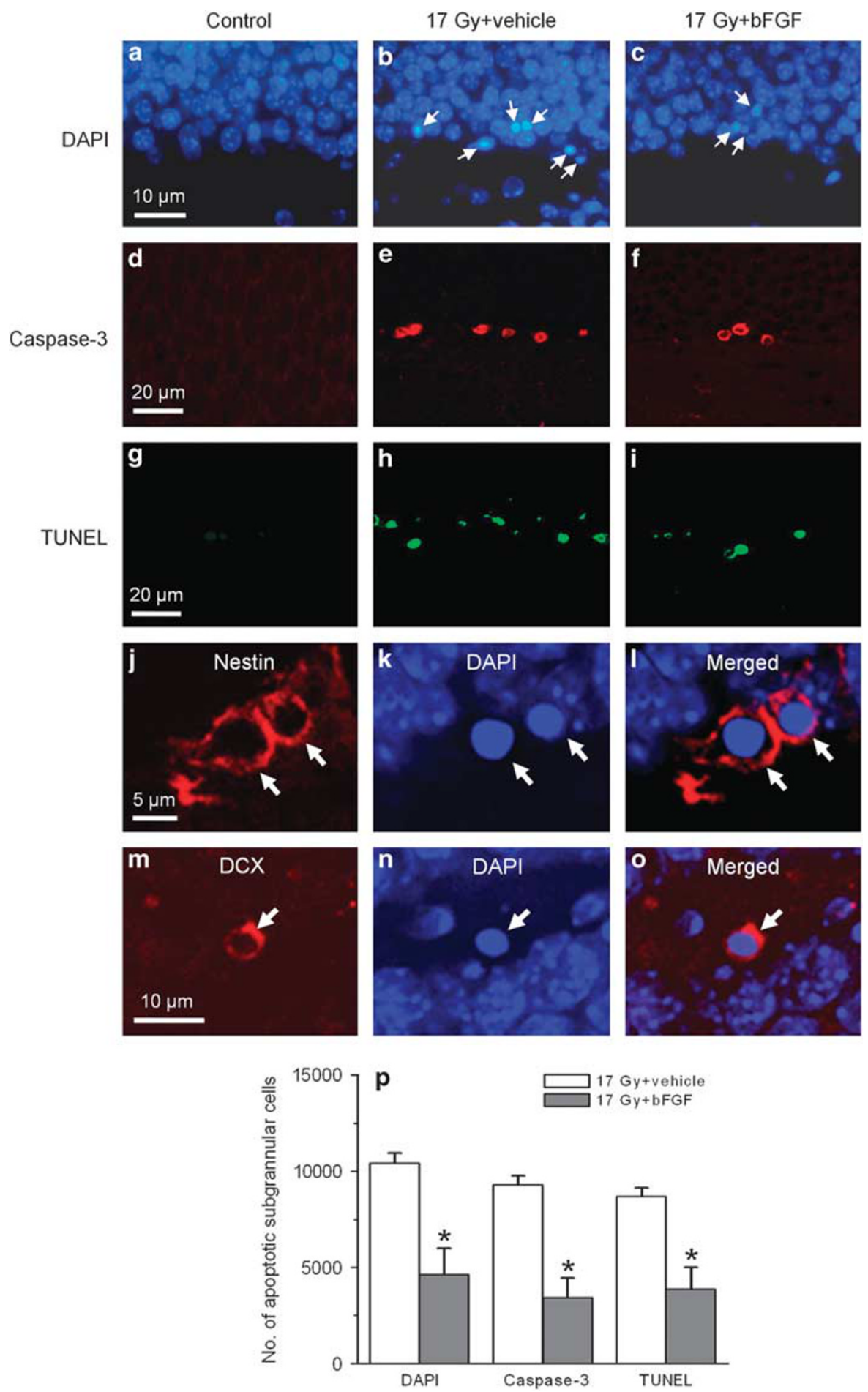

Figure 6 Intravenous bFGF attenuates radiation-induced apoptosis of neural progenitors in the SGZ of the dentate gyrus. The apoptotic response of subgranular cells in the dentate gyrus after irradiation is attenuated after intravenous bFGF as assessed using nuclear morphologies upon DAPI (arrows, a-c), caspase-3 (red, d-f) or TUNEL (green, $\mathbf{g}-\mathbf{i}$ ) staining. Apoptotic cells (arrows) demonstrate immunoreactivity for nestin (arrows, $\mathbf{j}-\mathbf{I}$ ) and DCX (arrows, $\mathrm{m}-\mathrm{o}$ ), phenotypic markers for neural progenitors. A significant reduction in DAPI, caspase-3 or TUNEL-positive subgranular cells is observed in mice given intravenous bFGF compared with vehicle controls ( ${ }^{*} P<0.05, t$-test; $p$ ). Data represent means \pm S.E. using a minimum of three mice per experimental group

response to hypoxia. Exposure to hypoxia in p53 null cells failed to augment caspase-3 and -7 activation, DNA fragmentation and apoptosis. ${ }^{14}$ The present data may suggest a model, whereby inhibition of endothelial injury reduces hypoxia-induced upregulation of HIF-1 and inhibits a component of p53-dependent apoptosis in NPCs induced by 
HIF-1 upregulation. Future work will need to be done to clarify the mechanistic role of the hypoxia/HIF-1 pathway in modulating the apoptotic response of NPCs after irradiation.

We observed no evidence of a threshold of this inhibitory effect as inhibition of NPC apoptosis associated with smpd1 deficiency was observed over the radiation dose range of 2-17 Gy used. Previous studies have suggested a threshold of $8-10$ Gy for the endothelial apoptotic response. ${ }^{14}$ In the present study, we observed dose-dependent endothelial cell apoptosis in the dentate gyrus over the range of single doses of 5-17 Gy. It is possible the apparent threshold dose reported was due to difficulty in quantifying these events at low doses in other organs and systems.

In summary, we provide evidence of an important role for endothelial cells in regulating p53-dependent apoptosis of NPCs after irradiation. Our findings may have important implications for the interactions among NPCs, endothelial cells and the neurogenic niche as novel targets to protect the CNS against genotoxic insults. These results add support to the critical role of endothelial cells not only in the self-renewal and differentiation of $\mathrm{NPCs}^{2}$ but also in their apoptotic fate after injury and in disease.

\section{Materials and Methods}

Animals. Ten-week-old male C57 mice, wild type $(+/+)$, heterozygous $(+/-)$ or knockout $(-/-)$, of the smpd1 gene and C57 mice $+I+,+I-$ or $-I-$ for the $p 53$ gene were used in this study as previously described. ${ }^{8}$ NPCs for the transplantation study were cultured from the brain of Tg/CAG-EGFP/B5Nagy mice (Jackson Laboratory, Bar Harbor, ME, USA) that express eGFP. All animals had free access to a standard rodent diet and water ad libitum throughout the study in the animal facility of the Sunnybrook Health Sciences Centre. All the animal protocols were approved by the institutional animal care committee, and experiments were performed according to the guidelines set by the Canadian Council on Animal Care. Genotyping was performed by PCR as previously described. ${ }^{8}$ eGFP mice were wild type for the $p 53$ and smpd1 genes.

Irradiation. Animals were anesthetized using an intraperitoneal injection of ketamine $(75 \mathrm{mg} / \mathrm{kg})$ and xylazine $(6 \mathrm{mg} / \mathrm{kg})$, immobilized in a customized jig and whole-brain was irradiated using $160 \mathrm{kV}$ X-rays (Model CP160; Faxitron $X$-ray, Wheeling, IL, USA) as previously described., ${ }^{8,25}$

Histopathology and immunohistochemistry. Under anesthesia with ketamine and xylazine, mice were perfused with $0.9 \%$ saline, followed by $4 \%$ paraformaldehyde. Mouse brains were retrieved, post-fixed for 3 days and cryoprotected in a $30 \%$ sucrose solution. Coronal sections that contained the hippocampus between 1.34 and $-3.08 \mathrm{~mm}$ relative to the bregma ${ }^{26}$ were cut at $40-\mu \mathrm{m}$ thickness and collected in tissue cryoprotectant solution in 96-well plates and stored at $-20^{\circ} \mathrm{C}$.

Antibodies against DCX, nestin, Sox2 and musashi-1 were used as markers for NPCs, and those against NeuN, GC, GFAP and CD31 were used to identify neurons, oligodendrocytes, astrocytes and endothelial cells, respectively. Free-floating sections were washed in PBS, incubated with DCX (1:2000; Abcam, Cambridge, MA, USA), Sox2 (1: 150; Stem Cell Technologies, Vancouver, BC, Canada), nestin (1:200; Millipore, Billerica, MA, USA), musashi-1 (1:250; Chemicon, Temecula, CA, USA), NeuN (1:500; Chemicon), GC (1:100; Chemicon), GFAP (1:200; DakoCytomation, Glostrup, Denmark) or CD31 (1:10; BD Biosciences, San Jose, CA, USA) in $2 \%$ donkey serum in PBS at $4{ }^{\circ} \mathrm{C}$ overnight. After washing in PBS, the sections were incubated with respective secondary antibodies conjugated to Cy3 (1:200; Jackson ImmunoResearch, West Grove, PA, USA). Sections were counterstained with DAPI to identify nuclei.

For detection of transplanted cells, sections were washed with PBS buffer twice for 5 min each in 24-well plates, followed by treatment in $1 \mathrm{~N} \mathrm{HCl}$ at $4{ }^{\circ} \mathrm{C}$ for $10 \mathrm{~min}$, $2 \mathrm{~N} \mathrm{HCl}$ at room temperature for $10 \mathrm{~min}$ and at $37^{\circ} \mathrm{C}$ for $20 \mathrm{~min}$ in a water bath. After washing in PBS, the sections were incubated with an antibody (1:400; Millipore) against BrdU at $4{ }^{\circ} \mathrm{C}$ overnight. A secondary antibody conjugated to Cy3 was used for visualizing transplanted cells. Sections were counterstained with DAPI.

Slides for TUNEL staining were processed using the In Situ Cell Death Detection Kit (Roche Diagnostics, Mannheim, Germany) as we described previously. ${ }^{6}$ Sections were incubated with proteinase $\mathrm{K}$ and were sequentially incubated with TUNEL reaction mixture (Roche Diagnostics) after washing in PBS. The tagged ends were labeled with fluorescein dUTP. Selected sections were also immunostained with the cleaved rabbit anti-caspase-3 (1:1000; Cell Signaling Technology, Beverley, MA, USA) followed by donkey anti-rabbit Cy3 secondary antibody (1:200; Jackson ImmunoResearch). Sections were counterstained with DAPI.

In our previous study, the apoptotic response in the SGZ quantified using TUNEL yielded similar results compared with data using morphological criteria. ${ }^{8}$ Quantification of apoptotic cells using the standard morphological criteria upon DAPI staining were found to be more robust than TUNEL because morphological characterization remains the gold standard for identification of apoptotic cells. ${ }^{27}$ Cells that showed nuclear condensation and fragmentation upon DAPI staining could be easily identified, and were considered apoptotic cells as we previously described. ${ }^{6,8,28}$ Selected results based on DAPI were confirmed using caspase-3 and TUNEL staining.

Stereological analysis. Apoptotic subgranular cells were counted within the dentate gyrus including a $50-\mu \mathrm{m}$ hilar margin of the SGZ as previously described. ${ }^{8,29}$ Cell counting was performed using a Zeiss Imager M1 microscope with the Stereo Investigator software (MicroBrightField, Williston, VT, USA). The observer was blinded to the treatment. Cells were counted using a counting frame and a sampling grid of $75 \times 75 \mu \mathrm{m}^{2}$ at a magnification of $\times 63$. Every seventh section was used as the periodicity of sections sampled. For the number of CD31positive apoptotic endothelial cells, every fourth section was used, for a total of eight sections. A counting frame size equal to the sampling grid of $140 \times 90 \mu \mathrm{m}^{2}$ was used at a magnification of $\times 63$. For the transplantation study, every fifth section was used for a total of 10 sections to encompass the hippocampus. BrdUlabeled and eGFP cells were counted exhaustively using a counting frame and a sampling grid of $90 \times 90 \mu \mathrm{m}^{2}$. All other stereological parameters were otherwise the same.

The coefficient of error was between 0.03 and 0.06 in all the stereological studies. The estimated number of the target cells in at least three animals was calculated as the mean of the number of the target cells in the right and left dentate gyrus of the mouse brain. Before cell counting, all the sections were reviewed to ensure completeness of immunostaining throughout the entire thickness of the tissue.

Primary culture of neural progenitors. Eight to ten-week-old smpd1 $+/+$, smpd1-/,$- p 53+/+, p 53-/-$ and eGFP mice were anesthetized as above and killed by cervical dislocation. The mouse brain was removed and washed in ice-cold D-PBS. Olfactory bulb, cerebellum, meninges and large blood vessels were quickly removed. The periventricular region of the lateral ventricles and hippocampus were dissected out, harvested and thoroughly washed in ice-cold D-PBS. ${ }^{30}$ The tissues were cut into $1-2-\mathrm{mm}^{3}$ pieces, digested using papain-protease-DNase 1 in DMEM medium for $25 \mathrm{~min}$ at $37^{\circ} \mathrm{C}$ and mechanically triturated. The cells were pelleted at $200 \mathrm{~g}$ for $5 \mathrm{~min}$, resuspended in $0.9 \mathrm{M}$ sucrose and Hank's balanced salt solution and centrifuged at $800 \times g$ for $10 \mathrm{~min}$. The sediment was resuspended in DMEM/F12 medium and passed through a $100-\mu \mathrm{m}$ cell strainer (BD Biosciences) and pelleted. The isolated cells were washed twice and seeded onto a culture plate fed with the DMEM/F12 medium containing $100 \mathrm{U} / \mathrm{ml}$ penicillin/streptomycin, B27 supplement, bFGF $(10 \mathrm{ng} / \mathrm{ml})$ and epidermal growth factor $(E G F, 20 \mathrm{ng} / \mathrm{ml})$. The medium was changed every other day. Neurospheres were formed after 7-10 days in culture.

To determine the multipotential properties of NPCs, neurospheres cultured from $p 53+/+$, p53-I- and smpd1 $+/+$, smpd1-I- or eGFP mice were mechanically dissociated into single-cell suspensions and plated onto four-chamber cell culture slips pre-coated with poly-L-ornithine (Sigma, St. Louis, MO, USA) and laminin (Millipore). Cells were fed with DMEM/F12 medium containing100 U/ml penicillin/streptomycin, B27 supplement and 10\% FBS. After 10 days of growth, cells were fixed with $4 \%$ paraformaldehyde in PBS for $10 \mathrm{~min}$ at room temperature and then washed twice with PBS. Antibodies against GC or GFAP were diluted $1: 300$, and antibodies against MAP2 or $\beta$ III tubulin (Millipore), phenotypic markers for neurons, were diluted 1:200 with an Antibody Diluent (Dako, Burlington, ON, Canada). Cells were incubated with the specific antibodies at $4{ }^{\circ} \mathrm{C}$ overnight. Following washing with PBS, Cy3 secondary antibodies 
(Jackson ImmunoResearch) were added $(1: 100)$ and incubated at room temperature for $2 \mathrm{~h}$. Cellular nuclei were stained with DAPI. After washing and mounting, the cells were analyzed under fluorescent microscopy.

Irradiation of neural progenitors and assessment of apoptosis. Neurospheres were mechanically dissociated into single-cell suspensions and plated onto culture dishes pre-coated with poly-L-ornithine (Sigma) and fed with DMEM/F12 medium containing penicillin/streptomycin, B27 supplement, bFGF and EGF. The medium was changed every other day for a week until cells grew to confluence. Cells were then given a single dose of $5 \mathrm{~Gy}$, a dose previously shown to induce an apoptotic response in neural progenitors in vitro. ${ }^{31}$ At $24 \mathrm{~h}$ after irradiation, the medium, D-PBS washing buffer and cells detached with $0.25 \%$ trypsin/EDTA (1:1 in volume diluted in D-PBS) were collected and pelleted at $600 \times g$ for $5 \mathrm{~min}$ and washed with D-PBS. The cells were fixed with $4 \%$ paraformaldehyde in PBS for $10 \mathrm{~min}$ at room temperature and then washed twice with PBS. TUNEL staining was performed according to the manufacturer's instructions (Roche Diagnostics). In brief, cells were resuspended and treated with a solution of $0.1 \%$ Triton $\mathrm{X}-100$ and $0.1 \%$ sodium citrate for $5 \mathrm{~min}$ at room temperature, then pelleted and washed twice with PBS for 5 min each. Cells were resuspended in $50 \mu \mathrm{l}$ of reaction mixture, incubated at $37^{\circ} \mathrm{C}$ for $60 \mathrm{~min}$ and washed once with PBS. Quantification of TUNEL-stained cells was performed by flow cytometry (FACSCalibur Flow Cytometer, BD Biosciences, Missisauga, ON, Canada) using the CellQuest software (BD Biosciences).

For manual counting, cell nuclei were counterstained using DAPI and TUNEL. The apoptotic response was expressed as percentage of TUNEL-stained cells or percentage of nuclei with nuclear condensation or fragmentation after DAPI staining. The results represented the average of a minimum of five experiments, and a minimum of 500 cells were counted per experiment

Transplantation of eGFP NPCs. A pilot study revealed that some apoptotic eGFP NPCs after irradiation in vitro demonstrated loss of eGFP fluorescence. Progenitors were thus allowed to incorporate $\operatorname{BrdU}(1 \mu \mathrm{M})$ for 3 days prior to transplantation as a second method to identify transplanted cells. The pilot study showed no effect of this BrdU protocol on cell viability of neural progenitors. Neurospheres derived from eGFP mice were mechanically dissociated into cell suspension. The cells were filtered with a $70-\mu \mathrm{m}$ cell strainer and washed twice with DMEM/F12 medium. The cells were then plated onto six-well culture plates pre-coated with poly-L-ornithine and fed with DMEM/F12 medium containing penicillin/streptomycin $(100 \mathrm{U} / \mathrm{ml})$, B27 supplement, bFGF $(10 \mathrm{ng} / \mathrm{ml})$, EGF $(20 \mathrm{ng} / \mathrm{ml})$ and BrdU $(1 \mu \mathrm{M})$. The cells were grown for 3 days in the medium. Subconfluent cells were detached with pipette, dissociated into single-cell suspensions, filtered with a $40-\mu \mathrm{m}$ strainer and washed three times with DMEM F12. After assessing cell viability and counting, BrdU-labeled eGFP NPCs were prepared to a concentration of 35000 cells/ $\mu$ l of DMEM/F12 medium. Over $99 \%$ of eGFP cells were found to have incorporated BrdU.

Transplantation was performed in 5-week-old smpd1 $+1+$ or smpd1 -1 mice. Animals were anesthetized using an intraperitoneal injection of anesthetic cocktail as described above. Animals were placed in a stereotactic frame (Kopf Small Animal Stereotaxtic 900, Tujunga, CA, USA). Following a midline incision to expose the bregma, four burr holes were drilled bilaterally using the following coordinates with reference to the bregma, site 1 and 2: right and left, $-1.8 \mathrm{~mm}$; lateral, $\pm 1.1 \mathrm{~mm}$; dorsal to ventral, $2.4 \mathrm{~mm}$; site 3 and 4: right and left, $-2.6 \mathrm{~mm}$; lateral, $\pm 1.6 \mathrm{~mm}$; dorsal to ventral, $2.7 \mathrm{~mm}$. A $1.5-\mu$ l volume of suspension of eGFP/BrdU-NPCs was injected at each site at a speed of $1 \mu \mathrm{l} / \mathrm{min}$. The syringe remained in place for $2 \mathrm{~min}$ after injection to allow pressure release and cell dispersion. Thus, a total of about 210000 neural progenitors were delivered into the hippocampus. The craniotomy was closed with no. 3 or 5 suture monofilament. Buprenorphin $(0.05-0.1 \mathrm{mg} / \mathrm{kg})$ was administered subcutaneously before and after the procedure. All the surgical procedures are performed using aseptic surgical techniques. No antibiotics were given. Animals transplanted with neural progenitors received a single dose of 17 Gy at 5 weeks (10-week-old) after transplantation.

Intravenous administration of bFGF. Endothelial cell apoptosis following irradiation in various organs including the CNS has shown to be inhibited by intravenous administration of bFGF, $8,11,12$ Because bFGF does not cross the blood-brain barrier, we used intravenous bFGF as a pharmacological approach to determine the effects of inhibition of endothelial cell apoptosis on apoptosis of neural progenitors after irradiation. Ten-week-old male C57 mice, wild type for $p 53$ and smpd1, were given three injections of bFGF (R\&D System, Minneapolis,
MN, USA) at $50 \mu \mathrm{g} / \mathrm{kg}$ in a vehicle of $1 \mathrm{mM}$ dithiothreitol and $0.1 \%$ bovine serum albumin, immediately before and immediately after and $1 \mathrm{~h}$ after irradiation, a dose schedule previously shown to inhibit endothelial cell apoptosis after irradiation. ${ }^{8}$ For quantification of the apoptotic response, animals were killed at $8 \mathrm{~h}$ after irradiation.

Statistical analysis. There was a minimum of three mice per dose per genotype in all the in vivo experiments. All data represented the means \pm S.E.M. Statistically significant difference between control and irradiated mice was determined using t-test and one-way ANOVA followed by Tukey's post test. The significance of irradiation dose and genotype on the apoptotic response was determined using two-way ANOVA followed by Bonferroni post test. Data were considered statistically significant at $P<0.05$. All the statistical tests were twosided. Statistical analyses were performed with the GraphPad Prism 4 (GraphPad Software, San Diego, CA, USA).

\section{Conflict of Interest}

The authors declare no conflict of interest.

Acknowledgements. The work was supported by a grant from the Canadian Cancer Society Research Institute (CSW).

\section{Author contributions}

$\mathrm{FL}$ and YQL performed the experiments and contributed in analyzing data and writing manuscript. IA contributed in interpreting data and writing manuscript. CSW designed the experiments and contributed in assembling data, interpreting data, writing manuscript and approving manuscript.

1. Zhao C, Deng W, Gage FH. Mechanisms and functional implications of adult neurogenesis. Cell 2008; 132: 645-660.

2. Shen Q, Goderie SK, Jin L, Karanth N, Sun Y, Abramova N et al. Endothelial cells stimulate self-renewal and expand neurogenesis of neural stem cells. Science 2004; 304: 1338-1340.

3. Hahn P, Lindsten T, Lyubarsky A, Ying GS, Pugh Jr EN, Thompson CB et al. Deficiency of Bax and Bak protects photoreceptors from light damage in vivo. Cell Death Differ 2004; 11: 1192-1197.

4. Gudkov AV, Komarova EA. The role of p53 in determining sensitivity to radiotherapy. Nat Rev Cancer 2003; 3: 117-129.

5. Shinohara C, Gobbel GT, Lamborn KR, Tada E, Fike JR. Apoptosis in the subependyma of young adult rats after single and fractionated doses of X-rays. Cancer Res 1997; 57 : 2694-2702

6. Chow BM, Li YQ, Wong CS. Radiation-induced apoptosis in the adult central nervous system is p53-dependent. Cell Death Differ 2000; 7: 712-720.

7. Mizumatsu S, Monje ML, Morhardt DR, Rola R, Palmer TD, Fike JR. Extreme sensitivity of adult neurogenesis to low doses of X-irradiation. Cancer Res 2003; 63: 4021-4027.

8. Li YQ, Aubert I, Wong CS. Abrogation of early apoptosis does not alter late inhibition of hippocampal neurogenesis after irradiation. Int J Radiat Oncol Biol Phys 2010; 77: 1213-1222.

9. Herzog KH, Chong MJ, Kapsetaki M, Morgan JI, McKinnon PJ. Requirement for Atm in ionizing radiation-induced cell death in the developing central nervous system. Science 1998: 280: 1089-1091.

10. Santana P, Peña LA, Haimovitz-Friedman A, Martin S, Green D, McLoughlin M et al. Acid sphingomyelinase-deficient human lymphoblasts and mice are defective in radiationinduced apoptosis. Cell 1996; 86: 189-199.

11. Peña LA, Fuks Z, Kolesnick RN. Radiation-induced apoptosis of endothelial cells in the murine central nervous system: protection by fibroblast growth factor and sphingomyelinase deficiency. Cancer Res 2000; 60: 321-327.

12. Li YQ, Chen P, Haimovitz-Friedman A, Reilly RM, Wong CS. Endothelial apoptosis initiates acute blood-brain barrier disruption after ionizing radiation. Cancer Res 2003; 63: 5950-5956.

13. Marathe S, Schissel SL, Yellin MJ, Beatini N, Mintzer R, Williams KJ et al. Human vascular endothelial cells are a rich and regulatable source of secretory sphingomyelinase. Implications for early atherogenesis and ceramide-mediated cell signaling. J Biol Chem 1998; 273: 4081-4088.

14. Fuks Z, Kolesnick R. Engaging the vascular component of the tumor response. Cancer Cell 2005; 8: 89-91.

15. Fike JR, Rosi S, Limoli CL. Neural precursor cells and central nervous system radiation sensitivity. Semin Radiat Oncol 2009; 19: 122-132. 
16. Wu D, Song BW, Vinters HV, Pardridge WM. Pharmacokinetics and brain uptake of biotinylated basic fibroblast growth factor conjugated to a blood-brain barrier drug delivery system. J Drug Target 2002; 10: 239-245.

17. Mirzadeh Z, Merkle FT, Soriano-Navarro M, Garcia-Verdugo JM, Alvarez-Buylla A. Neural stem cells confer unique pinwheel architecture to the ventricular surface in neurogenic regions of the adult brain. Cell Stem Cell 2008; 3: 265-278.

18. Shen Q, Wang Y, Kokovay E, Lin G, Chuang SM, Goderie SK et al. Adult SVZ stem cells lie in a vascular niche: a quantitative analysis of niche cell-cell interactions. Cell Stem Cell 2008; 3: 289-300.

19. Paris F, Fuks Z, Kang A, Capodieci P, Juan G, Ehleiter D et al. Endothelial apoptosis as the primary lesion initiating intestinal radiation damage in mice. Science 2001; 293: 293-297.

20. Garcia-Barros M, Paris F, Cordon-Cardo C, Lyden D, Rafii S, Haimovitz-Friedman A et al. Tumor response to radiotherapy regulated by endothelial cell apoptosis. Science 2003; 300: $1155-1159$

21. Gulbins E, Kolesnick R. Raft ceramide in molecular medicine. Oncogene 2003; 22: 7070-7077.

22. Stancevic $B$, Kolesnick R. Ceramide-rich platforms in transmembrane signaling. FEBS Lett 2010; 584: 1728-1740.

23. Deng X, Yin X, Allan R, Lu DD, Maurer CW, Haimovitz-Friedman A et al. Ceramide biogenesis is required for radiation-induced apoptosis in the germ line of $\mathrm{C}$. elegans. Science 2008; 322: 110-115.

24. Fuks Z, Alfieri A, Haimovitz-Friedman A, Seddon A, Cordon-Cardo C. Intravenous basic fibroblast growth factor protects the lung but not mediastinal organs against radiation-induced apoptosis in vivo. Cancer J Sci Am 1995; 1: 62.
25. Mahmoud-Ahmed AS, Atkinson S, Wong CS. Early gene expression profile in mouse brain after exposure to ionizing radiation. Radiat Res 2006; 165: 142-154.

26. Paxinos G, Franklin K. The Mouse Brain in Stereotaxic Coordinates. 2nd edn. Academic Press: London, 2001.

27. Sierra A, Encinas JM, Deudero JJ, Chancey JH, Enikolopov G, Overstreet-Wadiche LS et al. Microglia shape adult hippocampal neurogenesis through apoptosis-coupled phagocytosis. Cell Stem Cell 2010; 7: 483-495.

28. Gassmann M, Heinicke K, Soliz J, Ogunshola OO, Marti HH, Hofer T et al. Non-erythroid functions of erythropoietin. Adv Exp Med Biol 2003; 543: 323-330.

29. Wu KL, Li YQ, Tabassum A, Lu WY, Aubert I, Wong CS. Loss of neuronal protein expression in mouse hippocampus after irradiation. J Neuropathol Exp Neurol 2010; 69: 272-280.

30. Benouaich-Amiel A, Simon JM, Delattre JY. Concomitant radiotherapy with chemotherapy in patients with glioblastoma. Bull Cancer 2005; 92: 1065-1072.

31. Limoli CL, Giedzinski E, Baure J, Rola R, Fike JR. Redox changes induced in hippocampal precursor cells by heavy ion irradiation. Radiat Environ Biophys 2007; 46: 167-172.

Cell Death and Disease is an open-access journal published by Nature Publishing Group. This work is licensed under the Creative Commons Attribution-NonCommercial-No Derivative Works 3.0 Unported License. To view a copy of this license, visit http://creativecommons.org/licenses/by-nc-nd/3.0/

Supplementary Information accompanies the paper on Cell Death and Disease website (http://www.nature.com/cddis) 